\title{
EFL Teachers' Perceptions of Using Graphic Organizers in the Language Classroom
}

\author{
Dr. Nurah Alfares \\ Umm AlQura University, College of Education \\ Department of curriculum and instruction
}

\begin{abstract}
This study investigates teachers' perceptions of using graphic organizers (GOs) in the EFL (English as a Foreign Language) classroom. The aim was to explore teachers' behavior and perceptions regarding the use of GOs in EFL lessons. Mixed qualitative methods were used: classroom observations of six Saudi EFL teachers were conducted to investigate their behavior when using GOs in lessons; reflective reports were obtained from the same six teachers to investigate their perceptions of using GOs in lessons; and the teachers were interviewed to allow their behavior and reflections to be understood in greater depth. The findings show that these teachers found the use of GOs to be beneficial. However, some of them were uncomfortable using GOs, because they struggled to manage their time in class and because the low level of their students prevented them from obtaining the maximum benefits.
\end{abstract}

Keywords: graphic organizer, EFL, interaction, cognitive theories

\section{INTRODUCTION}

In this article, Saudi teachers' perceptions of using graphic organizers (GOs) in the EFL classroom are explored. The teachers' behavior when using GOs in lessons is examined, as are their reflections on using GO. An important issue with GOs is that, although they may help EFL teachers to improve their teaching, some teachers find them difficult to use. Thus, it is hoped that this study will help EFL teachers to understand the benefits of using GOs in their lessons in terms of improved student outcomes. Moreover, the findings will increase teachers' understanding, based on their own reflections, of the difficulties of using GO, which may relate to the teachers' own methods and processes or to the learners themselves. This exploration of teachers' behavior and their perceptions of using GOs in their lessons opens up opportunities for further experimental research into which kinds of GO are most useful and how improvements in student outcomes obtained from using GOs can be measured.

\section{GRAPHIC ORGANIZERS AND LEARNING}

Egan (1999) defines a GO as "a visual representation of knowledge, a way of structuring information, and of arranging essential aspects of an idea or topic into a pattern using labels." The structure in which new information is presented may have a positive or negative effect on learning. Ausubel (1963) believed that the methods used by teachers to represent information can stimulate learning; a suitable organizer can help students to establish associations between new information and what they have previously learned. Ausubel (1963) also showed that the mind organizes and stores information in a systematic way. New information about a concept is added into the existing context of categories, called a schema, that contains existing knowledge about the concept. GOs arrange information to complement the context, thereby facilitating learning. 
Previous research has shown that GOs can facilitate learners in understanding complex materials, as using a GO can help to activate learners' schemata. According to Dye (2000), "schema theory states that new information must be linked to preexisting knowledge." GOs are important in education, because visual illustrations focus on key elements of knowledge and the relationships between concepts, thus helping learners to gain a full understanding that words alone cannot convey (Jiang \& Grabe, 2007).

In Ausubel's theory, cognitive structures can organize new information for students in a hierarchical way, from high-level, general concepts down to very specific concepts; learners can internalize new information with existing information through the thinking process (Malone \& Dekkers, 1984). In such cases, meaningful learning can take place, because the cognitive structures of the learners become stronger by connecting new information to existing information. Schema theory builds on this with the claim that GO facilitates that connection.

Learning to think is a crucial skill for enhancing comprehension. Teachers often use methods in which learners are passive, and this makes it difficult for learners to extract meaning from the lesson content; instead, teachers should use methods that enable learners to construct meaning from context. This implies activating learners' thinking, and using strategies to make their learning more active. Previous research has proved that GOs can help learners to construct meaning and improve their comprehension (Alvermann \& Boothby, 1986; Darch, Carnine, \& Kameenui, 1986; Horton, Lovitt, \& Bergerud, 1990).

According to Loretta (2008), GOs can be classified into a number of categories: KWL (Know, Want to know, Learned) charts, history frames, word maps, concept maps, inquiry charts, and Venn diagrams. The most common of these are KWL charts, which allow a teacher-led approach to the introduction of new topics. History frames allow students to look at historical events and to break down information in order to enhance their comprehension. Word maps can help students to analyze new or difficult vocabulary from different viewpoints, whereas concept maps allow them to engage in more depth with complex ideas. Inquiry charts offer learners a way of organizing information gathered during their research (for example, into columns according to topic). Venn diagrams can be used to compare two ideas, events, or people. Mind maps can also be considered as a type of GO, since they focus on finding relationships between ideas; they could also be called relationship maps (Davies, 2010). Such maps have many benefits for students: they help them to be active in their learning, to enhance their thinking, and to organize information in a meaningful way (Krasnic, 2011). Other types of GO include semantic maps and knowledge maps, which are used to find new information and explain new concepts (Jonassen, Beissner, \& Yacci, 1993).

\section{GRAPHIC ORGANIZERS AND LANGUAGE LEARNING}

Previous studies have demonstrated the benefits of using GOs for language learning, and particularly for helping learners to enhance their comprehension at different levels and in different language learning skills (Boykin, 2015; DiCecco \& Gleason, 2002; Ermis, 2008; Liu, Chen, \& Chang, 2010; Newman, 2007; Pan, 2006; Ponce \& Mayer, 2014; Vakilifard, 2008).

GOs are closely connected to cognitive theories, since they can help learners to recall information and access existing knowledge. Marzano, Pickering, and Pollock claimed that GOs "enhance the development of non-linguistic representations in students and, therefore, enhance the development of that content" (2001, p. 73). Using GOs in teaching can also help in the production of linguistic representations; Jenson (2005) emphasizes that teachers should be 
familiar with how to help learners to construct meaning from information and improve their comprehension.

Ellis (2004) stated that GOs help with the organization of information and make complex information easier to process, thereby facilitating the process of comprehension. A further benefit of GOs is that they can increase creativity and flexibility of thinking, which enables learners to see information as a whole, and to identify and organize the relationships between different elements (Krasnic, 2011). Similarly, GOs can help learners to identify key concepts and important information, which allows them to focus on critical thinking (Ellis, 2004). GOs can also help learners to take a systematic approach to their learning (Bromley, Irwin-DeVitis, \& Modlo, 1995).

It is acknowledged as good practice for EFL teachers to make effective use of gestures, pictures, objects, and charts to encourage learners to make connections between information. Walker and Antaya-Moore (1999) characterized GOs as thinking tools that can help ESL students to enhance their understanding in the context of long-term memory, since it enables them to connect language and content. Baxendell (2003) claimed that a consistent routine of using GOs in the classroom helps learners to become strategic learners, so that they are able to reapply or generalize from what they have learned.

Furthermore, GOs can improve classroom management and teachers' instructions (Ritchie \& Gimenez, 1995), and they can help language learners to engage in discussion and learn in a meaningful context (Walker \& Antaya-Moore, 1999). Researchers have reported that a mixedability classroom is the perfect place to use a GO, because it creates opportunities for learners to learn differently depending on their preferred style.

\section{Aims}

\section{AIMS, METHODS, AND DATA ANALYSIS}

A systematic review of English language studies in Saudi Arabia reveals that Saudi students typically have a low level of English proficiency and low levels of achievement (Alhawsawi, 2013; Al-Johani, 2009; Al-Khairy, 2013a; Alrabai, 2014; Alrabai, 2016; Alrashidi \& Phan, 2015; Alseweed, 2009; Faruk, 2013; Rahman \& Alhaisoni, 2013; Rajab, 2013). In one study, nearly $70 \%$ of Saudi students attributed their low level of English proficiency to defective teaching in intermediate and high schools, which created obstacles to meaningful learning in English lessons (Habbash \& Idapalapati, 2016). Unfortunately, a large number of Saudi EFL students experience difficulties in understanding basic English grammar and therefore cannot form various sentence types (Alamin \& Ahmed, 2012; Al-Hassaani, 2016) or grammatical structures (Aljumah, 2011). One of the most important barriers to English proficiency is lack of practice; this applies to all language skills, but particularly to speaking. A further reason for the low levels of proficiency is the lack of application of strategies that can aid learner comprehension.

In Saudi schools, there is disagreement regarding the purpose of teaching English and the methods and strategies used and encouraged by the Ministry of Education (Al-Seghayer, 2011). As Al-Seghayer pointed out, the common methods of teaching English in Saudi schools are the audio-lingual method, the direct method, cognitive-code learning, and grammar translation. These traditional methods of teaching focus more on content than on using language, and they are less useful than might be expected in helping EFL learners to communicate and contribute to the process of learning. Previous research has found that, in Saudi schools, learners study English with an emphasis on content and language knowledge rather than on using English in communicative situations. The promotion of such methods through the curriculum prevents 
Saudi teachers being advised or encouraged to adopt current strategies that could help students to use English in class.

In Saudi Arabia, recent research in EFL has been quite limited; more emphasis has been on materials and teacher preparation than on methods and strategies of teaching. The literature shows that teachers do not usually help learners to learn independently; this affects how students learn and practice the English language, in that they receive new knowledge but are unable to make use of it. Teaching EFL requires a process that enables students to understand the language gradually; for example, teachers can start with very general or simple topics that are familiar to students and then go more deeply into these topics with discussion of details. Since language learners struggle to learn EFL in Saudi Arabia, it is advisable for teachers to use current strategies and techniques to improve the teaching process. Before EFL learners are introduced to the main content of a lesson, they may need key words that enable them to activate their existing knowledge and recall relevant information. Unfortunately, EFL teachers in Saudi classrooms may not spend sufficient time helping learners activate their schemata. This results in passive teacher-student and student-student interaction during lessons. Using a GO to introduce information relevant to the lesson can help students to engage in discussion with their peers to figure out for themselves the information required.

Since the aim of this study is to explore teachers' perceptions of using GOs in their lessons, three questions were identified to explore the phenomenon in detail:

(1) How do Saudi EFL teachers use GOs in lessons?

(2) How do Saudi EFL teachers perceive the strategy of using GOs in lessons?

(3) What are the challenges for Saudi EFL teachers in using GOs in lessons, and what other strategies do they like to use?

\section{Methods}

Three qualitative methods were used to answer the research questions and to explore the use of GOs: classroom observations were conducted to answer the first research question, and reflective reports and interviews were carried out to answer the second and third research questions. I began data collection by talking about the benefits of GOs and the methods and tools for using them in EFL lessons. I obtained the agreement of six teachers at schools selected at random in the city of Makkah to participate in the study. I suggested some GO models (see Appendix 4,5 and 6) that they could start using in their lessons. Some of the teachers used the suggested models, and others created their own models but they nearly similar to the given models (see Appendix 9 for an example). I asked the participating teachers to write a reflective report after each lesson on how the GO worked for them and their students and how it impacted the lesson structure, the information conveyed, and the learners' participation ( see Appendix 1 for the specified questions for the reflective report). The teachers kept diaries about their experiences during the period when they were carrying out GO-based activities, and they wrote reflections on their progress after each lesson. In terms of classroom observation, I attended lessons given by each of the six teachers, observing how they used the GOs in their lessons (see Appendix 2 for the observation sheet) ; these observations helped me to understand their behavior in depth. Finally, I interviewed the teachers after they completed their teaching using GOs in order to explore further their perceptions and to understand in depth some of the behaviors noted in the observations.

The interview questions focused on the teachers' experiences of using certain GO models in their lessons (see Appendix 3 for the interview questions), the changes they saw over the course of the lessons, and the challenges they faced in using GOs in their lessons. Since this is a qualitative study, I adopted a thematic approach to analyzing the research data. I began by 
reading through the data for each teacher, using all three methods to understand each case in depth. Then I read through the data for all the teachers, applying one method at a time, to identify emerging themes. I will discuss these themes in the data analysis section.

\section{Data Analysis}

To identify and develop the themes, I analyzed separately the data gathered using each method, thereby examining every finding using all three methods. It is essential to provide indepth insight into participants' perceptions of different elements of the same phenomenon (Denzin, 1978). Therefore, I used a coding process to identify similar passages, using labels based on topics, terms, concepts, ideas, phrases, and key words. Then I gave each of the codes a name to provide an indication of the idea or concept that supported the stated categories. Finally, I numbered the topics based on the terms, concepts, ideas, phrases, and key words found in each source, and I listed and transferred these to three separate concept maps to verify whether the data from different sources was similar. Combining data from the three methods was necessary for purposes of reliability, validity, consistency, and interpretation (Patton, 1999; 2001). Comparison of the statements in each concept map confirmed that similar data had been obtained from the different sources.

\section{FINDINGS}

Because I used thematic analysis to answer the three research questions, I will first present the themes that clarify the teachers' behaviors when they were using GOs. I will go on to present the themes that clarify their perceptions of using GOs. Finally, I will present the findings relating to the other strategies that the teachers liked to employ and the challenges they faced in using GOs.

\section{Teachers' Behavior When Using GOs \\ Using GOs in lessons.}

The classroom observations indicated that the GO strategy was applied in the first part of each lesson: all the participating teachers distributed worksheets to students to help them engage in a discussion before starting the new lesson. The teachers' primary aim was to help learners activate existing knowledge; their secondary aim was to help the learners to use the GO to form a general idea or to access preliminary information about the lesson topic. Therefore, the majority of the participating teachers used the GO as a brainstorming strategy at the beginning of the lesson.

Working on the GOs was beneficial for the classroom dynamic, as the teachers asked students to work in groups, and this provided opportunities to share knowledge and to help each other. Some of the teachers played an active role while the students were working on the GO worksheets, moving around the classroom to support and scaffold groups who were struggling to complete the GO. This seemed to help students to become more confident about completing their work with their colleagues.

Most of the teachers allowed students to spend between five and 10 minutes working on the GO worksheets. When I observed these classes, it seemed to me that five minutes was not enough for most students, because they needed time to share knowledge with other learners, to discuss certain points, and to clarify their understanding. The interaction and communication among students was better in the classes where the teacher allowed up to 10 minutes. This was because the students were able to share and discuss their knowledge before completing the GO. 


\section{Encouraging interaction through use of GOs}

The teachers made effective use of GOs; working on the GO sheets together encouraged students to increase their interaction. Most of the teachers set up a competition between groups to encourage students to complete the GO sheets cooperatively. Some teachers awarded marks for this, and the groups with the highest marks received a small reward at the end of the lesson.

As a technique for helping students to cope with their difficulties in communicating in English, some teachers allowed students to use the Arabic language if they were not able to fill the GO worksheets in English; this encouraged them to participate. It was clear from the observations that when the teacher gave students the green light to use their native language, the students played an active part in the discussion and shared their knowledge to figure out the information that they had to find; after that, they worked on how to translate the information into English and record them to the GO worksheet. Given the students' belief that their limited use of the English language is a barrier to their participation in English lessons, the teachers' strategy of allowing them to use their native language was very helpful in encouraging them to start of , then they allow them to translate the main information in English. It was obvious after their discussion, they take an active role in the lesson.

Some teachers used different procedures to help learners work actively in the lesson, such as games and fun activities aimed at encouraging student cooperation and increasing interaction. Other teachers decided to be direct with students: they talked to them explicitly about the benefits of spending time at the beginning of the lesson completing the GO worksheets. These teachers wanted the students to be aware of the benefits of using the GO, so that this awareness would inform their interaction and encourage them to take an active role during the lesson.

\section{Teachers' Perceptions of Using GOs in Lessons Teachers' reflections on the benefits of using GOs}

The interviews showed that some teachers found GOs useful for organizing and arranging the stages of a lesson: students started working on GO sheets at the beginning of the lesson, they moved on to an in-depth exploration of the topic, and in the last part of the lesson they summarized what they had learned. Therefore, the GOs helped to organize lessons into stages that progressed from very general knowledge to more specific knowledge. As Teacher 4 said:

Using a GO helped me to brainstorm students' ideas at the beginning of the class. They can guess and try out ways of thinking and writing with the members of their group. It also makes the introduction of the lesson easier and more motivating. The GO helped my students to organize their ideas, and it made the lesson livelier and smoother.

Some teachers offered another perspective: they thought that GO could bring excitement to their lessons as well as keeping students active. Some found that the GO prepared students for the topic of the lesson and made the teaching process easier for both the teacher and the students. For the teachers, using the GO was helpful in structuring and organizing the lesson. For the students, the benefit was increased comprehension of the lesson content.

Some teachers claimed that the GO helped students to take responsibility for their learning, since it encouraged them to access their previous knowledge and to share it with others. As Teacher 2 said:

I found using GO very helpful and easy to use, and it helped them in understanding the topic by themselves. Also, through the GO, the students were able to participate during the lesson and give feedback at the end. 
Some teachers reported that the GO helped students to participate and interact more during the lesson and that it helped students to share ideas with others. It was also claimed that GOs enabled students to figure out the objectives of the lesson and to identify the most important information.

\section{Teachers' comparisons of lessons with and without GOs}

I used the interviews to explore the teachers' perceptions of the differences between lessons with and without GOs. Some teachers reported that in GO lessons students were able to share their ideas with others and that their communication and interaction increased. Others reflected that in non-GO lessons, teachers might be tempted to present the lesson directly without giving the students a chance to activate their existing knowledge. As Teacher 1 said: Before I used a GO, the students in the class were not interactive, and I just gave them an introduction-I did not elicit the introductory material from them. But after I started to use a GO, the students in the class became more interactive and there was enough time in the class. In addition, I formed a clearer impression of the students, which gave me the chance to deal with them more effectively.

The effect on the early stages of a lesson was particularly remarkable. Some teachers reported that with the GO they were able to find time for a discussion at the beginning of the lesson. Others teachers emphasized how, before using GOs, they had depended on visual tools (such as videos and pictures) to introduce the lesson. This method of presenting the topic and outlines of the lesson gave students the chance to develop the oral skill only; in contrast, the use of GO allowed them to develop two skills, speaking and writing. As Teacher 4 said:

Before I used the GO, I was finding it hard to prepare students for the lesson. Sometimes I depended on questions about a video or a picture, but this only led to students responding orally. Instead, using the GO helped them with two skills, writing and speaking. The students started with what they knew and read it out loud. The lesson turned out to be very effective and enjoyable, especially in terms of reading skills.

Moreover, some teachers reported that GOs helped them to become aware of and evaluate students' existing knowledge; this enabled them to adapt the lesson content to avoid repeating what the students already knew. In addition to promoting students' thinking, the GO helped them to be active in class and encouraged them to be more imaginative. Teachers also found that GOs helped their lessons to go more smoothly, since students were able to draw on their own ideas about the lesson topic before they started work on less familiar content.

\section{Teachers' preferences regarding recent strategies in EFL}

In the interviews, I explored the teachers' preferences for using other strategies in English lessons, and here I will present the most common perspectives. Some teachers reported a preference for strategies that encourage students to learn communicatively, and others stated that they like to encourage cooperative strategies between students. Similarly, some teachers preferred to use thinking strategies (such as think-pair-share) to help familiarize learners with the main idea of the context in, for example, a reading lesson. Problem-solving and brainstorming strategies were also popular with these teachers, who considered them as thinking strategies. As Teacher 4 said:

It depends on the kind of lesson. For example, in a vocabulary lesson, I use picture reading strategies where students can easily guess the meaning from the pictures. Synonym strategies can also help in this kind of lesson. For a reading lesson, I use think-pair-share, so that students can guess the meaning or the main idea of every 
paragraph and discuss it in their groups or with a classmate. For grammar, I use mind mapping.

Most of the teachers expressed a preference for strategies that can be considered as a kind of GO, including mind mapping (especially popular for grammar lessons) and KWL strategies. However, a few preferred using traditional methods, particularly when presenting information and checking students' comprehension of the new information. These teachers believed that students would not take seriously more recent strategies that encourage interaction and communication; they were also concerned that the lesson would not have tangible outcomes. As Teacher 1 said:

I prefer the traditional methods. I think it is more effective when I give students an introduction, ask them about it, and then give them suitable feedback.

This could explain why some teachers appeared reluctant to implement newer strategies: they felt more comfortable controlling the lesson and giving students knowledge and instructions directly.

\section{Challenges for Saudi EFL Teachers in Using GOS}

From the interview findings, I identified a number of challenges facing teachers who use GOs in their lessons. One of the most common issues is the time-consuming nature of GO activities; in a lesson of between 30 and 35 minutes, there may not be sufficient time to help students interact during their work on the GO sheets. Another common challenge related to students' weak level of writing in English. This resulted in some difficulties, particularly in completing the GO sheets.

However, it is clear that the teachers worked hard to manage and overcome these difficulties. As Teacher 4 said:

One of the challenges I faced was the students' responses to the GO. But they did very well, because they want something new to work on. Another issue was their spelling mistakes and their poor writing. But over and over, they tried to share and think together and write correctly. The last thing is that not all students shared their ideas, and some of them were not interested in sharing. But as a teacher, I helped them and tried to encourage them so that they started doing it and tried to work together.

Another challenge that emerged from the interviews is that the shyness of students prevented them from discussing their ideas with each other. This required careful consideration, and some teachers came to the conclusion that GOs were not suitable for certain types of lesson. For example, some teachers reported that it was difficult to use GOs for listening skills, although they worked well for other skills (grammar, writing, vocabulary). As Teacher 2 said:

I found it helpful more in grammar, writing, and vocabulary skills. But otherwise there was not any increase in interaction, especially in listening skills. Maybe they were not trained in listening.

\section{DISCUSSION}

Although some teachers made effective use of GOs, other teachers preferred to use traditional methods, which they claimed would be more manageable for them. Previous research has demonstrated the positive effects of using GOs: they give teachers opportunities to explain and illustrate ideas and to contribute to enhancing students' comprehension. This applies particularly to vocabulary in EFL, where different kinds of graphical presentation can be used (National Institute of Child Health and Human Development [NICHD], 2000). Furthermore, previous studies have indicated the benefits of GOs for students. They help students to use 
their skills to collect relevant information and to understand the relationships between different ideas, to organize and synthesize information, and to apply their thinking to real-life situations (National Institute of Child Health and Human Development [NICHD], 2000).

In the present study, it appeared that the teachers used GOs mainly for brainstorming and activating students' knowledge at the start of a new lesson. This is in line with previous studies, which found that GOs helped teachers to encourage students to activate their existing knowledge. This had a positive impact on students' critical thinking, since it helped them to discover relationships between what they had learned and what they wanted to learn (Bromley, Irwin-DeVitis, \& Modlo, 1995). Although all the teachers in this study used a GO at the beginning of their lessons, previous studies have identified benefits of using GOs at the application stage. This is because GOs can help students to put into practice what they have learned and to apply their knowledge appropriately (Dye, 2000).

The findings of this study showed that one of the difficulties teachers faced in using GOs was the low level of the students: they lacked the proficiency required to complete the GO. However, previous studies have recommended using GOs at all levels of English in EFL learning, suggesting that partially completed GOs could be given to lower-level learners (Boykin, 2015; DiCecco \& Gleason, 2002; Ermis, 2008; Liu, Chen, \& Chang, 2010; Newman, 2007; Pan, 2005; Ponce \& Mayer, 2014; Vakilifard, 2008; Yaman, 2006). Keene and Zimmerman (1997) claimed that teachers need to encourage low-level students to make connections when they read a text, as this will enhance their comprehension. Therefore, using GOs could help learners, particularly low-level learners, to make connections and to discover relationships between ideas. This is because a GO is a way of structuring information and arranging it into patterns using labels, a process that facilities the acquisition of new knowledge (Bromley, Irwin-DeVitis, \& Modlo, 1995).

The finding that teachers made effective use of GOs is consistent with previous studies, which also noted a beneficial effect on the teachers' instructions. This is because a teacher's instructions can have a positive impact on a student's achievement; when students are fully aware of what they should do to complete the GO, this can enhance the sense of community among them (Ritchie and Gimenez 1995). The teacher's use of an effective structure can help students to engage in a discussion and enable them to learn in a meaningful context (Walker \& Antaya-Moore 1999). As a result, students can formulate what they have learned in a way that is more understandable for them and that better matches their preferred style. This makes GOs particularly suitable for mixed-ability EFL classes, because the learners can incorporate different ways of improving their comprehension.

The findings about how these EFL teachers use different strategies appear inconsistent with previous studies, which found that active learning strategies work best for EFL learners, since they need ways to facilitate the application of what they have learned. Ritchie and Gimenez (1995) concluded that GOs would be more effective in EFL learning than in other subjects. Further, Baxendell (2003) claimed that a GO needs to be organized in a coherent, consistent, and creative way for the most effective results. GOs should be easy, understandable, and straightforward; complicated and difficult GOs that require too much information from learners will have a negative impact on students' achievement (Baxendell, 2003).

To make the GO process easier for learners, teachers can include pictures, so that students can connect the pictures with words and use these connections to complete the GO successfully. Since GOs containing pictures can enhance students' comprehension, these will have a beneficial effect on language skills, and more specifically on reading comprehension. Helping 
language learners to organize their ideas about the content of a text could assist them to a much better comprehension of the text in terms of the main ideas, supporting details, facts, opinions, comparisons, and contrasts (Slavin, 2011).

In this study, some teachers found GOs to be unsuitable for certain types of lesson or for specific language skills, particularly listening. However, a meta-analysis of GO studies carried out by Kansızoğlu (2017) found that GOs had a greater positive effect on listening skills than on other skills. Writing and reading came next, and vocabulary and grammar may also have benefited from considerable positive effects. It is therefore recommended that EFL teachers use GOs for all language skills. Baxendell (2003) states that the consistent application of GOs can help students to become more independent learners, since it gives them the chance to reapply, generalize, and associate different skills, thus improving their own learning. There is a further point to note here: just as teachers can use a GO to check students' comprehension of a reading text, students can use a GO to self-assess their own comprehension.

Some teachers expressed the view that using non-traditional strategies would not be effective in language learning, on the grounds that students would not take the activities seriously. In this connection, Kansızoğlu's meta-analysis of 70 studies (2017) investigated the effects of using GOs in language learning compared with traditional methods, with a particular focus on student achievement. The meta-analysis concluded that 69 studies found a positive effect, whereas only one study indicated that GOs had a negative effect on language learning. This strongly suggests that there are considerable benefits of using GOs in language learning.

Some teachers in the present study mentioned that they found certain recent strategies, such as KWL, useful for EFL learning. A KWL chart is mainly concerned with developing background knowledge: with columns headed "what I know," "what I want to know," and "what I learned," it focuses more on concepts than on facts and is, in effect, a kind of GO. Therefore, even if EFL teachers use different terms (such as Venn diagram, concept map, and KWL), all these tools can be considered as varieties of GO and can have a positive effect on learners.

It should be borne in mind that imposing restrictions on certain teaching methods, or limiting them to particular levels of learner ability, is likely to be frustrating for some learners, leading to stress for students and their teachers. It is more motivated to implement strategies that have a positive impact on classroom instructions and organization, whatever the abilities of the learners. In this connection, Simmons et al (1988) investigated the effect of using GOs and found that EFL students using GOs had higher levels of achievement than EFL students not using GOs. A study by Griffin and Tulbert (1995) suggested that the use of GOs in the L2 reading classroom leads to better learning processes and better oral and written output.

In conclusion, the implication for EFL teachers is that they need to be aware of the importance of using GOs for successful learning, since GOs are based on cognitive learning strategies and are well adapted to recent teaching methodologies, such as the constructivist approach (McKnight, 2010, p. 1). When GOs are used appropriately in lessons, they can have a positive impact on learning outcomes while encouraging students to become more active and independent as learners. A further implication is that GOs can be considered for use at all educational levels, from pre-school to undergraduate; learners of any age can benefit from being encouraged to explore and build new knowledge (Strangman, Hall, \& Meyer, 2003).

\section{References}

Alamin, A. \& Ahmed, S. (2012). Syntactical and Punctuation Errors: An Analysis of Technical Writing of University Students Science College, Taif University, KSA. English Language Teaching, 5(5), 2-8. 
Al-Hassaani, A. (2016). A Case Study of Question Formations of the Saudi EFL Learners at Bisha University. English Language Teaching, 9(5), 54-64.

Alhawsawi, S. (2013). Investigating student experiences of learning English as a foreign language in a preparatory programme in a Saudi university (Unpublished doctoral dissertation). University of Sussex, Brighton, UK

Alvermann, D. E., \& Boothby, P. R. (1986). Children's transfer of graphic organizer instruction. Reading Psychology, $7(2), 87-100$.

Al-Johani, H. (2009). Finding a way forward the impact of teachers strategies, beliefs and knowledge on teaching English as a foreign language in Saudi Arabia (Unpublished doctoral dissertation). University of Strathclyde, Glasgow, Scotland, UK.

Aljumah, F. (2011). Developing Saudi EFL Students' Oral Skills: An Integrative Approach. English Language Teaching, 4(3), 84-89.

Al-Khairy, M. (2013a). English as a foreign language learning demotivational factors as perceived by Saudi undergraduates. European Scientific Journal, 9(32), 365-382.

Al-Khairy, M. (2013b). Saudi English-Major Undergraduates' Academic Writing Problems: A Taif University Perspective. English Language Teaching, 6(6), 1-12

Alrabai, F. (2014). A Model of Foreign Language Anxiety in the Saudi EFL Context. English Language Teaching, 7(7), 82-101.

Alrabai, F. (2016). Factors Underlying Low Achievement of Saudi EFL Learners. International Journal of English Linguistics, 6(3), 21-37.

Alrashidi, O. \& Phan, H. (2015). Education Context and English Teaching and Learning in the Kingdom of Saudi Arabia: An Overview. English Language Teaching, 8(5), 33-44.

Alseweed, M. (2009). Attitudes of Saudi Secondary School Level Students Towards Learning of English as a Foreign Language. Journal of Arabic and Human, Qassim University, 2(1), 9-22.

Al-Seghayer, K. (2011). English teaching in Saudi Arabia: Status, issues, and challenges. Riyadh, Saudi Arabia: Hala Printed Co.

Ausubel, D. P. (1963) The psychology of meaningful verbal learning. New York: Grune and Stratton.

Baxendall, B. W. (2003). Consistent, coherent, creative: The 3 C's of graphic organizers. Teaching Exceptional Children, 35(3), 46.

Boykin, A. L. (2015). The impact of computer-based graphic organizers with embedded self-regulated learning on the content area argumentative writing of typical and struggling writers (Doctoral dissertation). George Mason University College of Education and Human Development, Fairfax,

VA.

Bromley, K., Irwin-DeVitis, L., \& Modlo, M. (1995). Graphic organizers: Visual strategies for active learning. New York: Scholastic Professional Books.

Darch, C.B., Carnine, D.W., \& Kameenui, E.J. (1986). The role of graphic organizers and social structure in content area instruction. Journal of Reading Behavior, 18, 275-295.

Davies, M.(2011). Concept mapping, mind mapping and argument mapping: What are the differences and do they matter? Higher Education, 62, 279-301. doi:10.1007/s10734-010-9387-6.

Denzin, N. (1978): The Research Act: A Theoretical Introduction to Sociological Methods. New York: McGraw-Hill

DiCecco, V. M., \& Gleason, M. M. (2002). Using Graphic Organizers to Attain Relational Knowledge From Expository Text. Journal of Learning Disabilities, 35(4), 306-320. https://doi.org/10.1177/00222194020350040201

Dye, G. A. (2000). Graphic organizers to the rescue! Helping students link and remember information. Teaching Exceptional Children, 32(3), 72-76.

Egan, M. (1999). Reflections on effective use of graphic organizers. Journal of Adolescent \&l4 cluli Literacy, 42,641646.

Ellis, E. S. (2000). Makes sense accommodations: Strategic graphic organizer instruction. Tuscaloosa, AL:

Masterminds, LLC.

Ermis, S. (2008). Using graphic organizers to facilitate elementary students' comprehension of informational text. College Reading Association Yearbook, (29), 87-102. 
Faruk, S. (2013). English language teaching in Saudi Arabia: A world system perspective. Scientific Bulletin of the Politehnica University of Timisoara. Transactions on Modern Languages, 12(1-2), 73-80

Griffin, C. C., \& Tulbert, B. L. (1995). The Effects of Graphic Organizers on Students' Comprehension and Recall of Expository Text: A review of the Research and Implication of Practice. Reading and Writing Quarterly: Overcoming Learning Difficulties, 11(1), 73-89.

http://dx.doi.org/0.1080/1057356950110106...

Habbash, M. \& Idapalapati, S. (2016). Distinctiveness of Saudi Arabian EFL Learners. Advances in Language and Literary Studies, 7(2), 113-120.

Horton, S. V., Lovitt, T. C., \& Bergerud, D. (1990). The effectiveness of graphic organizers for three classifications of secondary students in content area classes. Journal of Learning Disabilities, 23, 12-22.

Jensen, E. (2005) Teaching With The Brain in Mind (2nd ed.), Association for Supervision and Curriculum Development, Alexandria : VA.

Jiang, X., \& Grabe, W. (2007). Graphic organizers in reading instruction: Research findings and issues. Reading in a Foreign Language, 19, 34-55.

Jonassen, D., Beissner, K., \& Yacci, M. A. (1993). Structural knowledge: Techniques for representing, conveying, and acquiring structural knowledge. Hillsdale, NJ: Lawrence Erlbaum.

Kansızoğlu, Hasan. (2017). The Effect of Graphic Organizers on Language Teaching and Learning Areas: A MetaAnalysis Study. TED EĞITiM VE BILIMM. 42. 10.15390/EB.2017.6777.

Keene, E.O., \& Zimmerman, S. (1997). Mosaic of thought: Teaching comprehension in a reader's workshop. Portsmouth, NH: Heinemann.

Krasnic, T. (2011). Concise learning: Learn more and score higher in less time with less effort. Alexandria, VA: Concise Books.

Li, L. F. (2008). The Image of Daniel: An Ancient Graphic Organizer. Journal of Research on Christian Education, $17(2), 217-224$.

Liu, P.L., Chen, C.J., \& Chang ,Y.J. (2010) Effects of a computer-assisted concept mapping learning strategy on EFL college students' English reading comprehension. Computers \& Education, 54(2): 436-445.

Malone, J., \& Dekkers, J. (1984). The concept maps as an aid to instruction in science and mathematics. School Science and Mathematics, 84(3), 220-231.

https://doi.org/10.1111/j.19498594.1984.tb09543.x

Marzano, R. J., Pickering, D., \& Pollock, J. E. (2001). Classroom instruction that works: Research-based strategies for increasing student achievement (p. vi, 178 p). Alexandria, VA: Association for Supervision and Curriculum Development.

McKnight, K. S. (2010). The teachers's big book of graphic organizers: 100 reproducible organizers that help kids with reading, writing, and the content areas. San Francisco, CA: Jossey-Bass.

National Institute of Child Health and Human Development. (2000). Report of the national reading panel: Teaching children to read: An evidence-based assessment of the scientific research literature on reading and its implications for reading instruction: Reports of the subgroups. Washington, DC: Author.

Newman, L. M. (2007). The effects of explicit instruction of expository text structure incorporating graphic organizers on the comprehension of third-grade students (Order No. 3297242). Available from ProQuest Dissertations \& Theses Global. (304852273).

Pan, L. (2006). The implication of schema theory, metacognition and graphic organizers in english reading comprehension for technical college students in taiwan (Order No. 3205304). Available from ProQuest Dissertations \& Theses Global. (304918164).

Ponce, H. R \& ,.Mayer, R. E. (2014). An eye movement analysis of highlighting and graphic organizer study aids for learning from expository text .Computers in Human Behavior .32-21 ,41 ,doi:10.1016/j.chb.2014.09.010

Simmons, D. C., Griffin, C. C., \& Kameenui, E. J. (1988). Effects of teacher-constructed pre- and post-graphic organizer instruction on sixth-grade science students' comprehension and recall. Journal of Educational Research, 82(1), 15-21.

Slavin, R. E. (2011). Educational Psychology: Theory and Practice. NY: Pearson 
Strangman, N., Hall, T., \& Meyer, A. (2003). Graphic organizers with UDL. Wakefield, MA: National Center on Accessing the General Curriculum.

Rahman, M. \& Alhaisoni, E. (2013). Teaching English in Saudi Arabia: Prospects and Challenges. Academic Research International, 4(1), 112-118.

Rajab, H. (2013). Developing speaking and writing skills of L1 Arabic EFL learners through teaching of IPA phonetic codes. Theory and Practice in Language Studies, 3(4), 653-659.

Ritchie, D., \& Gimenez, F. (1995). Effectiveness of graphic organizers in computer-based instruction with. Journal of Research on Computing in Education, 28(2), 221.

Walker, C, \& D Antaya-Moore. (1999). Thinking Tools for Kids. Edmonton, Alta: Edmonton Public Schools.

Vakilifard, A. (2008). The effects of the hierarchical concept map as an instructional strategy on second language learners' literal and inferential comprehension of expository text (Doctoral dissertation). University of Montreal Department of Didactic Faculty of Educational Sciences, Montreal, Canada.

Yaman, H. (2006). The effect of the concept map technique in grammar lessons during the second level of the primary education on the student success and the act of remembering (Doctoral dissertation). Marmara University, Institute of Social Sciences, İstanbul.

\section{APPENDIX 1 \\ THE DAILY REPORT AFTER USING GRAPHIC ORGANIZER IN EFL LESSON}

1- The topic of your lesson

2- The aims of your lesson

3- How did you organize the groups to work in the graphic organizer?

4- What kind of tasks did you give them?

5- How did you explain the interactive roles for the group members to fill in the graphic?

6- How did you motivate and encourage them to participate in filling the graphic organizer?

7- What are your reflections about impeded the graphic organizer into your lesson?

8- What are the students' reflections with the impeded graphic organizer? 


\section{APPENDIX 2 \\ AN OBSERVATION SHEET}

1- The name of the teacher's.

2- The topic of the lesson:

3- The kind of task:

4- How does the teacher introduce graphic organizer task to the students?

5- How do the students interact to complete the task?

6- How do the teacher scaffold learners to complete the task?

\section{APPENDIX 3 \\ THE INTERVIEW QUESTIONS FOR THE EFL TEACHERS AFTER USING GRAPHIC ORGANIZER}

1- General information

- Name

- Your Age

- Grade that you teach

- Number of students

2- What are the teaching methods that you prefer to apply them when you teach EFL?

3- What kind of strategies you use when you teach EFL, in the daily routine?

4- How do you think graphic organizer affect your lesson?

5- Can you compare between your lesson organization before you use graphic organizer and after you use graphic organizer?

6- Can you Compare between the students' interaction before and after you use the advanced graphic organizer?

7- What are the challenges for you to use the advance graphic organizer as brainstorming strategy in teaching EFL? 
APPENDIX 4

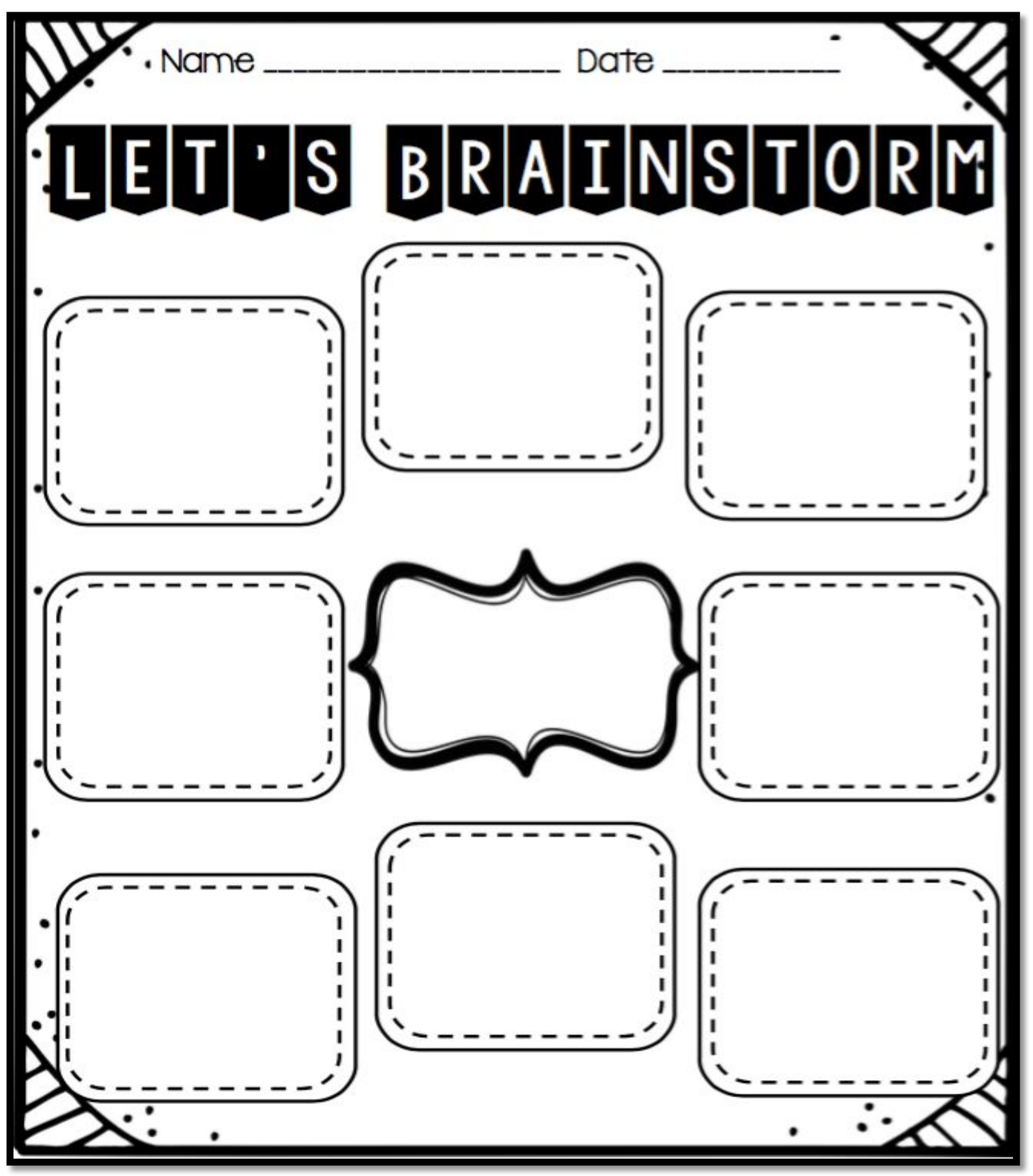




\section{APPENDIX 5}

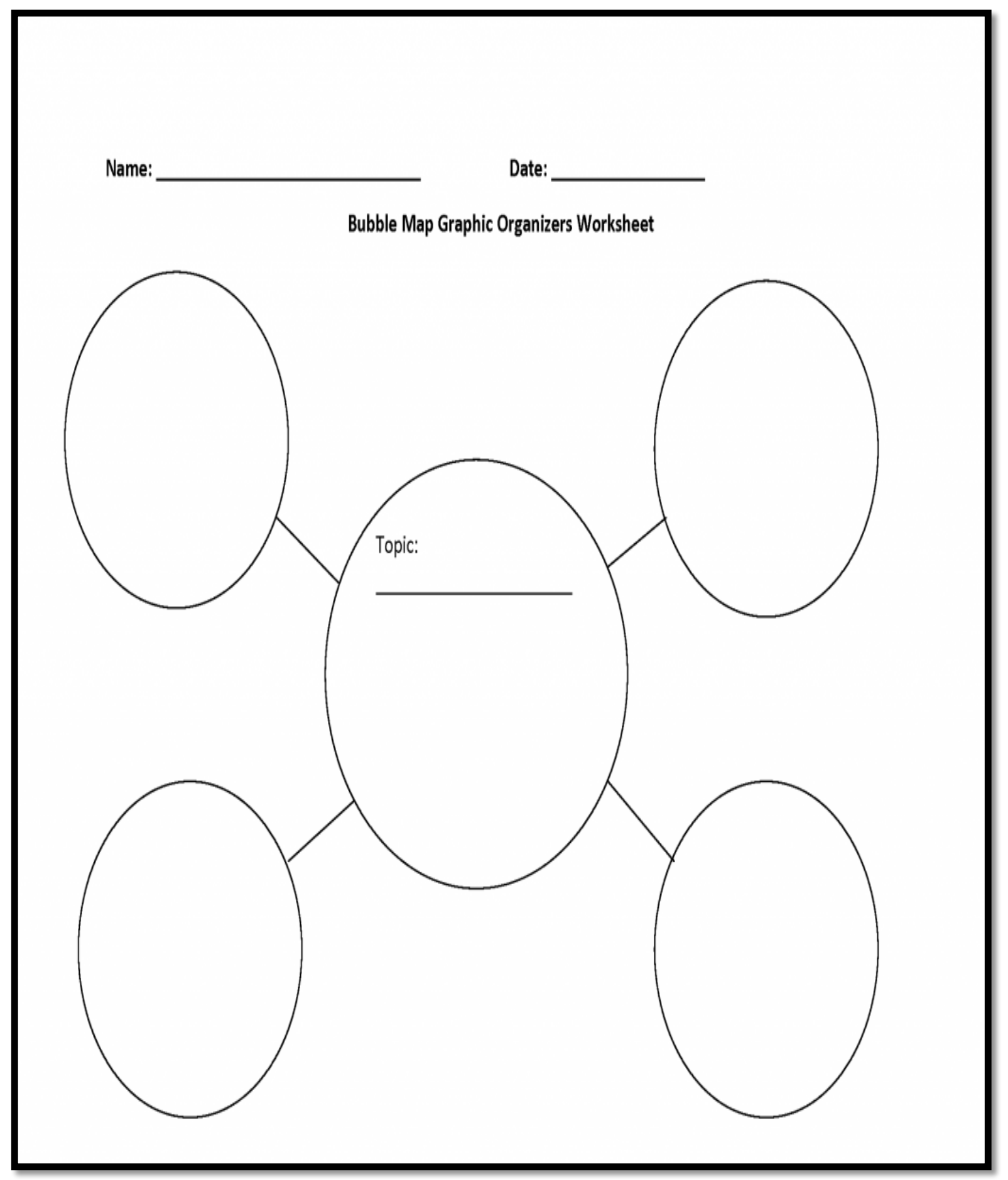


APPENDIX 6

Name:

Date:

Concept Mapping: Horizontal Flow Chart

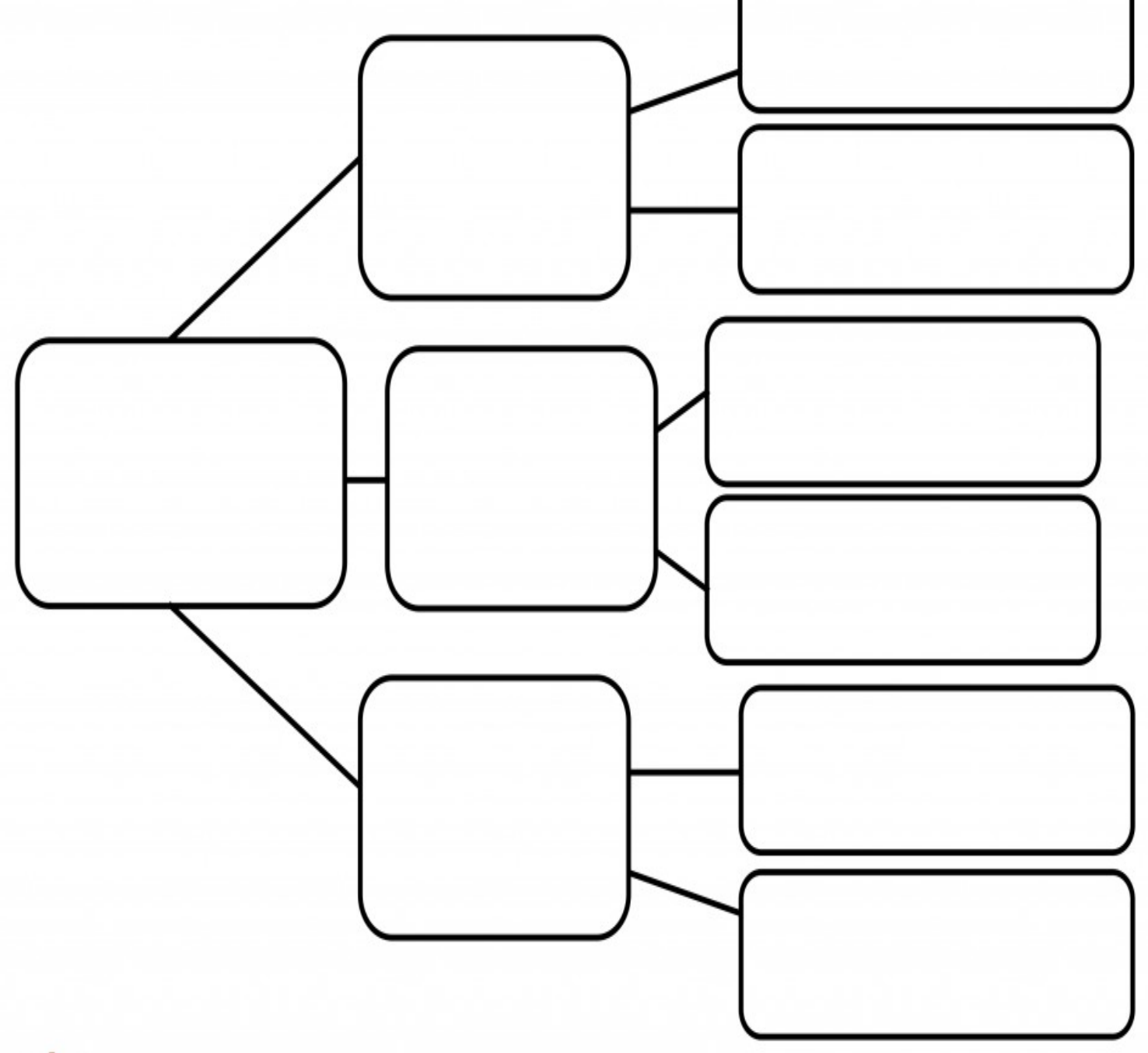




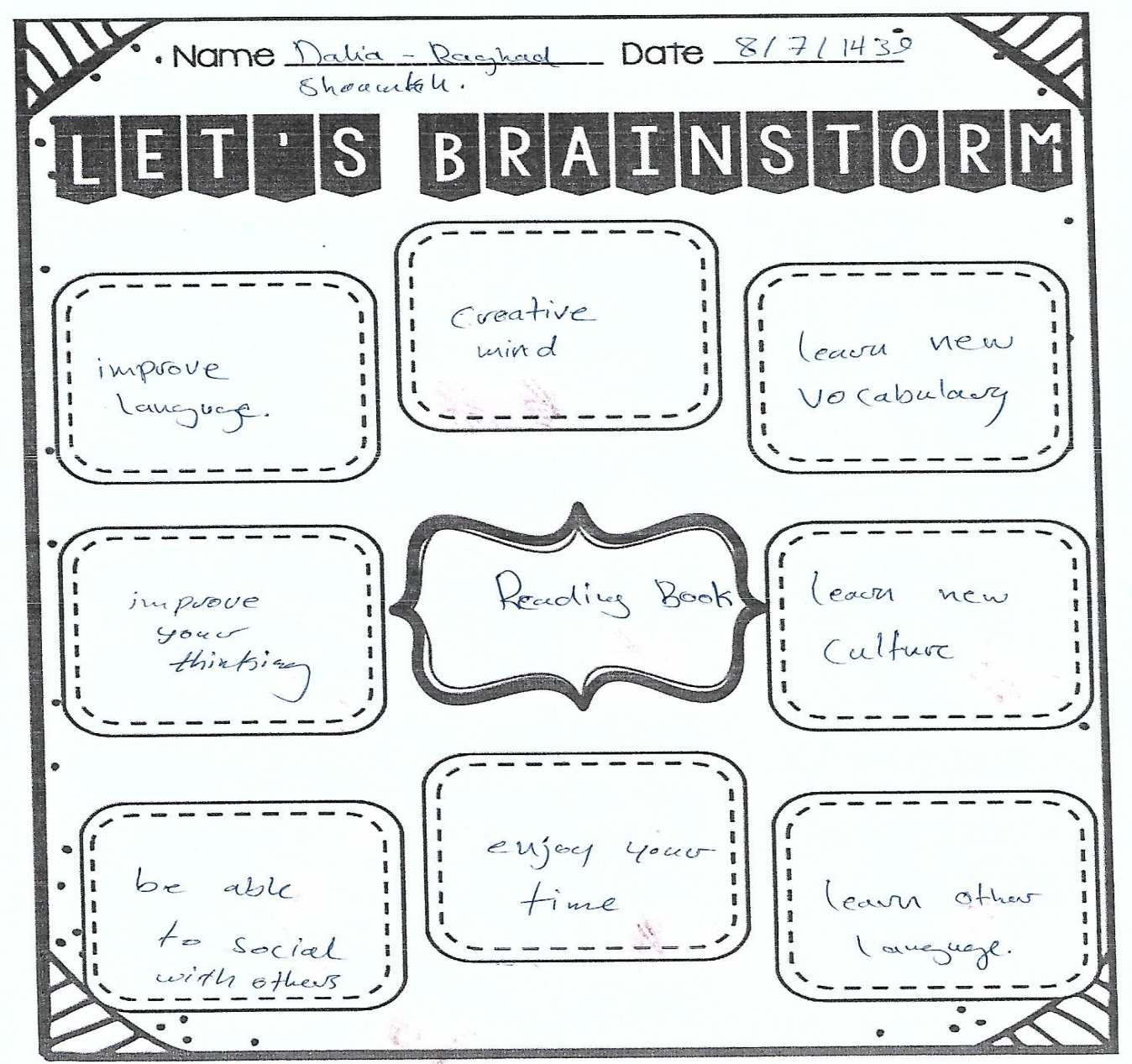




\section{APPENDIX 8}

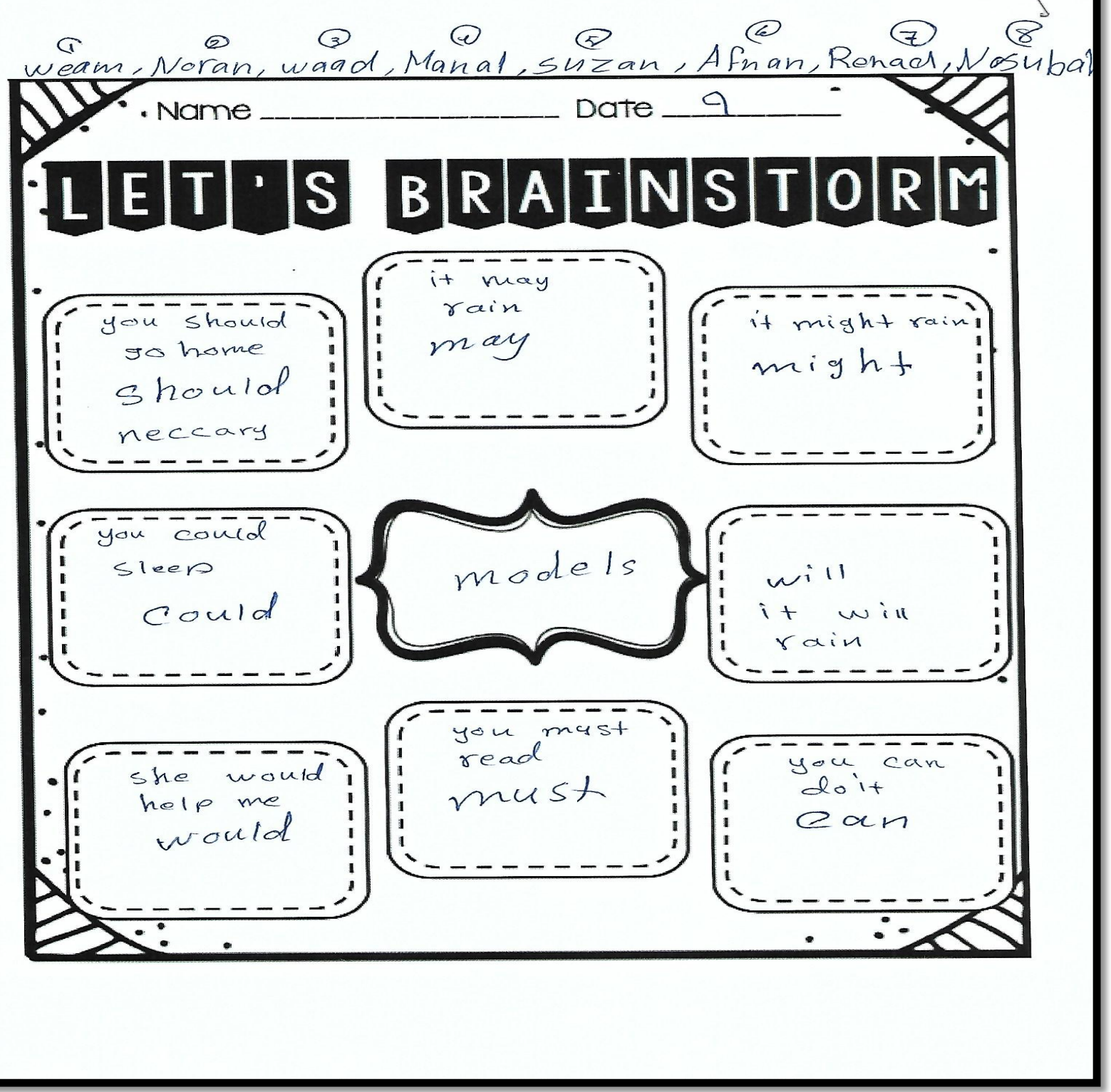




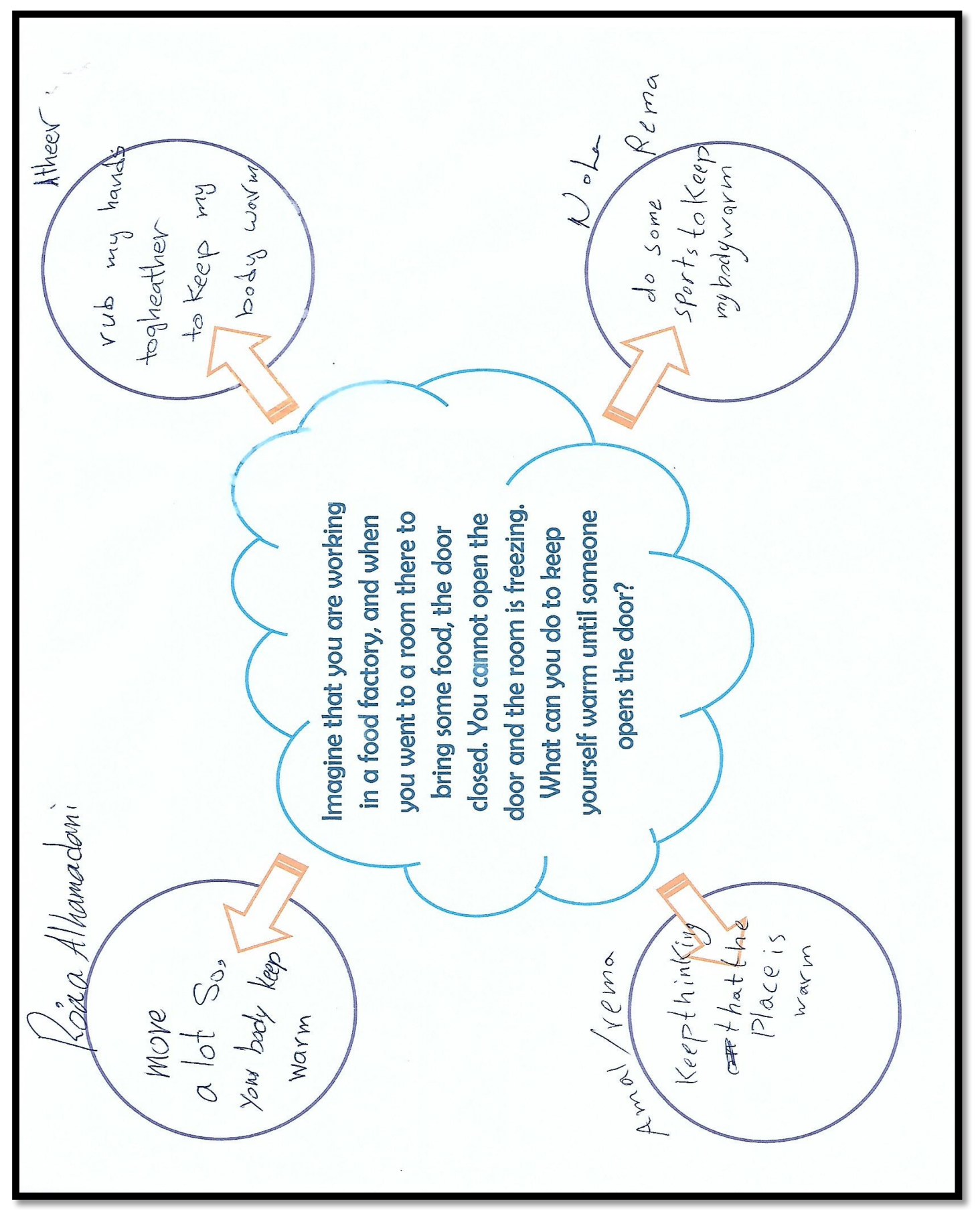

